\title{
A phase I open-label study evaluating the cardiovascular safety of sorafenib in patients with advanced cancer
}

\author{
Anthony W. Tolcher - Leonard J. Appleman • \\ Geoffrey I. Shapiro • Alain C. Mita • \\ Frank Cihon · Arthur Mazzu • Pavur R. Sundaresan
}

Received: 29 January 2010/ Accepted: 14 May 2010/Published online: 3 June 2010

(C) The Author(s) 2010. This article is published with open access at Springerlink.com

\begin{abstract}
Purpose To characterize the cardiovascular profile of sorafenib, a multitargeted kinase inhibitor, in patients with advanced cancer.

Methods Fifty-three patients with advanced cancer received oral sorafenib $400 \mathrm{mg}$ bid in continuous 28-day cycles in this open-label study. Left ventricular ejection fraction (LVEF) was evaluated using multigated acquisition scanning at baseline and after 2 and 4 cycles of sorafenib. QT/QTc interval on the electrocardiograph (ECG) was measured in triplicate with a Holter 12-lead ECG at baseline and after 1 cycle of sorafenib. Heart rate (HR) and blood pressure (BP) were obtained in duplicate at baseline and after 1 and 4 cycles of sorafenib. Plasma
\end{abstract}

Poster presentation of primary results on September 12, 2008, at the annual meeting of the European Society of Medicine and Oncology (ESMO), Stockholm, Sweden.

\section{A. W. Tolcher $(\bowtie)$}

START (South Texas Accelerated Research Therapeutics), 4319 Medical Drive, Suite 205, San Antonio

TX 78229, USA

e-mail: atolcher@start.stoh.com

L. J. Appleman

University of Pittsburgh Cancer Institute,

UPMC Cancer Pavilion, 5150 Centre Avenue,

Fifth Floor, Pittsburgh, PA 15232, USA

G. I. Shapiro

Early Drug Development Center, Department of Medical

Oncology, Dana-Farber Cancer Institute, Boston, MA, USA

\section{G. I. Shapiro}

Department of Medicine, Brigham and Women's Hospital, Harvard Medical School, 44 Binney Street, Dana 810A,

Boston, MA 02115, USA pharmacokinetic data were obtained for sorafenib and its 3 main metabolites after 1 and 4 cycles of sorafenib.

Results $\quad$ LVEF (SD) mean change from baseline was -0.8 $( \pm 8.6) \operatorname{LVEF}(\%)$ after 2 cycles $(n=31)$ and $-1.2( \pm 7.8)$ $\operatorname{LVEF}(\%)$ after 4 cycles of sorafenib $(n=24)$. The QT/QTc mean changes from baseline observed at maximum sorafenib concentrations $\left(t_{\max }\right)$ after 1 cycle $(n=31)$ were small (QTcB: $4.2 \mathrm{~ms}$; QTcF: $9.0 \mathrm{~ms})$. Mean changes observed after 1 cycle in BP $(n=31)$ and HR $(n=30)$ at maximum sorafenib concentrations $\left(t_{\max }\right)$ were moderate (up to $11.7 \mathrm{~mm} \mathrm{Hg}$ and $-6.6 \mathrm{bpm}$, respectively). No correlation was found between the AUC and $C_{\max }$ of sorafenib and its main metabolites and any cardiovascular parameters.

Conclusions The effects of sorafenib on changes in QT/QTc interval on the ECG, LVEF, BP, and HR were modest and unlikely to be of clinical significance in the setting of advanced cancer treatment.

\section{A. C. Mita}

Institute for Drug Development, Cancer Therapy and Research

Center, 7979 Wurzbach Road, Zeller Building, 4th Floor,

San Antonio, TX 78229, USA

F. Cihon

Clinical Statistics, Bayer Healthcare Pharmaceuticals Inc.,

PO Box 1000, Montville, NJ 07045, USA

A. Mazzu · P. R. Sundaresan

Pharmacodynamics, Bayer Healthcare Pharmaceuticals Inc., PO Box 1000, Montville, NJ 07045, USA 
Keywords Cardiovascular adverse event (CAE) . Left ventricular ejection fraction (LVEF) - Hypertension . QT/QTc interval · Sorafenib · Cardiovascular profile

\section{Introduction}

Small molecule inhibitors of the vascular endothelial growth factor receptor (VEGFR) that target tumor angiogenesis are accepted treatments for several advanced cancers. Recent studies have suggested that tyrosine kinase inhibitors (TKI) with molecular targets involved in angiogenesis may be associated with cardiac adverse events (CAEs), such as a decline in left ventricular ejection fraction (LVEF) and the development of congestive heart failure (CHF), myocardial infarction (MI), QT/QTc interval prolongation, and hypertension [1-10]. Sorafenib, an antiangiogenic multitargeted kinase inhibitor, is indicated for the treatment of patients with advanced renal cell carcinoma (RCC) and patients with unresectable hepatocellular carcinoma (HCC). Sorafenib inhibits B-Raf, VEGFR-2 and VEGFR-3, platelet-derived growth factor receptor (PDGFR)- $\beta$, stem cell factor receptor c-KIT, RET, and FLT-3 [11].

The inhibition of normal signaling pathways in cardiomyocytes that depend upon serine/threonine Raf kinases or the receptor tyrosine VEGFR and PDGFR kinases by sorafenib raises the possibility of cardiotoxicity [12-16]. However, reports of cardiotoxicity during treatment with sorafenib in two large randomized, placebo-controlled, double-blind, international phase III trials have been infrequent. In randomized studies for RCC [17] and HCC [18], the incidence of treatment-emergent cardiac ischemia/infarction AEs based on the final safety analysis was 2.9 and $2.7 \%$ in patients treated with sorafenib compared with 0.4 and $1.3 \%$ in the placebo groups in these trials, respectively. In the RCC phase III study, the safety analysis was performed comparing the randomized treatment groups (sorafenib versus placebo), as well as evaluating patients who were initially randomized to placebo and then given the option of crossing over to sorafenib based on positive findings from an independently assessed formal analysis of progression-free survival (PFS), which showed a significant doubling in median PFS with sorafenib over that with placebo. In a safety analysis update performed on a database 16 months post-crossover, $4.9 \%$ of patients randomized to the sorafenib group reported cardiac ischemia/infarction AEs [19]. Three patients (1.4\%) who crossed over from the placebo group to sorafenib also reported cardiac ischemia/infarction AEs while on sorafenib in this analysis. It is noteworthy that patients with coronary artery disease (CAD) or recent MI were excluded from these studies. A recent retrospective analysis of cardiovascular safety data from 18 studies of sorafenib monotherapy across multiple tumor types, however, reported a low overall rate of CHF and MI (1.6 and $1.5 \%$ of all patients, respectively), with treatment-emergent hypertension being reported in $18.6 \%$ of patients [20].

Although treatment with sorafenib does not appear to lead to cardiotoxicity, the full incidence and severity of CAEs that may occur with its administration are unknown because previous clinical trials with sorafenib have not specifically included cardiac end points. All clinical studies of sorafenib have recorded CAEs as part of the general safety monitoring for toxicity; the identification of CAEs was predominantly based on the occurrence of clinical symptoms. None of the trials were specifically designed to evaluate the full cardiovascular profile of sorafenib. The objective of this study was to further evaluate the effect of continuous sorafenib monotherapy on cardiovascular safety parameters, such as LVEF, QT/QTc interval, blood pressure (BP), and heart rate (HR) in cancer patients, and correlate any CAEs with sorafenib pharmacokinetics (PK) to enhance understanding of the cardiovascular profile of sorafenib.

\section{Materials and methods}

This open-label study of sorafenib enrolled patients with histologically or cytologically confirmed advanced solid tumors (excluding colorectal cancer) or lymphomas. Patients had to have a life expectancy of at least 12 weeks; adequate bone marrow, liver, and renal function; and an Eastern Cooperative Oncology Group Performance Status (ECOG PS) of 0 or 1 . Study eligibility criteria included baseline LVEF $\geq 45 \%$, systolic BP $\leq 170 \mathrm{~mm} \mathrm{Hg}$, diastolic $\mathrm{BP} \leq 100 \mathrm{~mm} \mathrm{Hg}$, and a QTc $<500 \mathrm{~ms}$. Therapy to control hypertension was allowed. Exclusion criteria included previous CHF $>$ New York Heart Association (NYHA) Class 2, cardiac arrhythmias requiring antiarrhythmic therapy other than beta blockers or digoxin, uncontrolled hypertension, history of HIV infection or chronic hepatitis $\mathrm{B}$ or $\mathrm{C}$, systemic anticancer treatment within 4 months or radiotherapy within 3 weeks of initiation of sorafenib, and prior or current use of type $1 \mathrm{~A}$ or 3 antiarrhythmics, anthracyclines, or anti-VEGF agents (including bevacizumab). Active CAD or MI $\leq 6$ months prior to study entry were allowed as long as LVEF was $\geq 45 \%$ at baseline. Patients were treated with oral sorafenib $400 \mathrm{mg}$ bid until progressive disease (PD) or intolerance to the drug. Although treatment was continuous, 28 days (4 weeks) of treatment was defined as 1 cycle. At the baseline visit occurring 2 days before the start of cycle 1 , assessments for QT/QTc interval, BP, HR, and PK were performed. All patients were required to be on a steady state of sorafenib 
Table 1 Study design and procedure schedule

\begin{tabular}{|c|c|c|c|c|c|c|c|c|c|c|c|}
\hline \multirow[t]{3}{*}{ Treatment } & \multirow[t]{3}{*}{ Screening } & \multicolumn{2}{|l|}{ Baseline } & \multicolumn{7}{|c|}{ Day 1 of cycle } & \multirow[t]{3}{*}{ End $^{\mathrm{a}}$} \\
\hline & & \multirow{2}{*}{-2 days placebo } & \multirow{2}{*}{-1 day $\operatorname{mox}^{b}$} & 1 & 2 & 3 & 4 & 5 & 6 & $\overline{\geq 7}$ & \\
\hline & & & & \multicolumn{7}{|c|}{ Sorafenib $400 \mathrm{mg}$ bid } & \\
\hline \multicolumn{12}{|c|}{ Cardiovascular evaluations } \\
\hline LVEF, MUGA scan & $\mathrm{X}$ & & & & & $\mathrm{X}$ & & $\mathrm{X}$ & & & $\mathrm{X}$ \\
\hline QT interval, $E C G^{\mathrm{c}, \mathrm{d}}$ & & $\mathrm{X}$ & $X^{e}$ & & $\mathrm{X}$ & & & & & & \\
\hline Supine $\mathrm{BP} / \mathrm{HR}^{\mathrm{c}, \mathrm{f}}$ & $\mathrm{X}$ & $\mathrm{X}$ & & & $\mathrm{X}$ & & & $\mathrm{X}$ & & & \\
\hline \multicolumn{12}{|l|}{ Other evaluations } \\
\hline PK & & $X^{g}$ & & & $\mathrm{X}$ & & & $\mathrm{X}$ & & & \\
\hline Safety & & $\mathrm{X}$ & $\mathrm{X}$ & & $\mathrm{X}$ & $\mathrm{X}$ & $\mathrm{X}$ & $\mathrm{X}$ & $\mathrm{X}$ & $\mathrm{X}$ & $\mathrm{X}$ \\
\hline Efficacy & $\mathrm{X}$ & & & & & $X$ & & $\mathrm{X}$ & & $\mathrm{X}$ & $\mathrm{X}$ \\
\hline
\end{tabular}

$L V E F$ left ventricular ejection fraction, $M U G A$ multigated acquisition scan, $E C G$ electrocardiograph, $B P$ blood pressure, $H R$ heart rate, $P K$ pharmacokinetics

${ }^{\mathrm{a}}$ End of treatment visit

b Moxifloxacin (QT positive control) $400 \mathrm{mg}$

c Pre-dose, 2, 4, 6, 8, $12 \mathrm{~h}$ post-dose

d Patients were in supine position for 10 min prior to measurement. Measurements were taken in triplicate

e Pre-dose, 0.5, 1, 2, 3, 4 h post-dose

${ }^{\mathrm{f}}$ Patients were in supine position for 5 min prior to measurement. Measurements were taken in duplicate; if the measurements differed by $\geq 10 \mathrm{~mm} \mathrm{Hg}$, a third BP measurement was taken, and the mean of the 3 measurements was calculated

g Pre-dose only

exposure (after $\sim 7$ days of dosing) for evaluation of cardiovascular safety parameters. The primary cardiovascular outcome measures were LVEF, QT/QTc interval, BP, and HR following continuous sorafenib monotherapy (refer to Table 1 for study design details).

\section{LVEF measure}

LVEF was assessed by multigated acquisition (MUGA) scan at baseline, after 2 and 4 cycles of sorafenib (day 1 of cycles 3 and 5, respectively), and at study discontinuation. The timing for LVEF measurements is consistent with the median time to onset of CAEs reported in studies with TKIs (8-16 weeks) $[4,7,9]$.

\section{QT/QTc interval measure}

Cardiac repolarization was measured as the time from the beginning of the $\mathrm{Q}$-wave to the point where the $\mathrm{T}$-wave returns to the isoelectric point (QT/QTc interval) on an electrocardiograph (ECG). The effect of steady state exposure to sorafenib on cardiac repolarization was measured in triplicate, at baseline, and after 1 cycle of sorafenib (day 1 of cycle 2). Measurements were recorded before taking sorafenib, and $2,4,6,8$, and $12 \mathrm{~h}$ postsorafenib administration using continuous ECG monitoring with a Mortara H-12 Plus, 12-Lead Digital Holter Recorder (Mortara Instrument, Milwaukee, WI, USA) [21]. The patients were in a supine position for $10 \mathrm{~min}$ prior to each time point. The ECGs were transmitted via graphic flash cards from the investigation sites to eResearch Technology (eRT, Philadelphia, PA, USA), which performed manual ECG measurements. At the baseline visit occurring 1 day before the start of cycle 1, QT/QTc intervals were also measured (in triplicate) for moxifloxacin oral 400-mg single dose as a positive control. Moxifloxacin, which produces a small $(5-10 \mathrm{~ms})$ increase in QT/QTc interval [22], was used to demonstrate the ability of the study to pick up this magnitude of effect. Measurements were recorded at baseline prior to moxifloxacin and $2 \mathrm{~h}$ post-moxifloxacin administration.

Blood pressure and heart rate measure

Supine BP and HR were recorded in duplicate, 1 min apart, at baseline and after 1 and 4 cycles of sorafenib (on day 1 of cycles 2 and 5, respectively). Measurements were recorded before patients received sorafenib, and 2, 4, 6, 8, and $12 \mathrm{~h}$ post-sorafenib administration using the Omron 907 Automated Blood Pressure Device (Omron, Bannockburn, IL, USA).

\section{Pharmacokinetic measure}

Quantitative analysis of sorafenib and its metabolites (BAY 43-9007, BAY 67-3472, BAY 68-7769) was 
performed using a fully validated HPLC-MS/MS assay described previously [23]. Patients were included in the PK analyses if they had plasma PK samples collected at baseline and after 1 cycle and/or 4 cycles of sorafenib (on day 1 of cycles 2 and/or 5, respectively). Blood samples for PK analyses were collected from patients after supine $\mathrm{BP} / \mathrm{HR}$ measurements at the following time points: before taking sorafenib, and 2, 4, 6, 8, and $12 \mathrm{~h}$ post-sorafenib administration. PK analyses included area under the plasma concentration versus time curve from time 0 to $12 \mathrm{~h}$ $\left(\mathrm{AUC}_{(0-12)}\right)$, maximum plasma concentration $\left(C_{\max }\right), t_{\max }$, and pre-dose plasma concentration $\left(C_{\text {trough,steady state }}\right)$.

\section{Safety and efficacy measures}

General safety evaluation (including laboratory safety) was carried out at screening, baseline, and on the first day of every cycle. The incidence, severity, and relationship of AEs to study drug were recorded using the National Cancer Institute-Common Terminology Criteria for Adverse Events (NCI-CTCAE) v3.0. Tumor measurements were performed at screening and after every 2 cycles while patients were receiving sorafenib. Tumor response was reviewed locally at each center using Response Evaluation Criteria in Solid Tumors (RECIST). Documented approval from the appropriate ethics committee(s)/institutional review board(s) was obtained for all participating centers/ countries prior to study initiation. Written informed consent was obtained from all patients.

\section{Statistical analyses}

The primary focus of this phase I study was to evaluate the effect of chronic sorafenib administration on cardiovascular safety parameters. To achieve the defined sample size of 35 patients who completed 4 or more cycles of sorafenib therapy, 53 patients were enrolled. The sample size was determined based on similar clinical studies with other compounds that evaluated changes from baseline in BP, $\mathrm{HR}$, and QT/QTc interval in advanced cancer patients, and was considered appropriate for identifying and evaluating clinically important changes in such cardiovascular parameters. Statistical analyses of each cardiovascular parameter summarized measurements for observed values and changes from baseline in a descriptive fashion.

\section{LVEF analysis}

To be included in LVEF analysis, patients were required to have a baseline LVEF value and at least 1 post-sorafenib LVEF value. The "primary analysis group" consisted of all treated patients who met the above criteria and received at least 1 dose of sorafenib. In addition, a "secondary analysis group" consisting of patients who had received $75 \%$ of all sorafenib doses, had missed less than 3 sorafenib doses in the week preceding the MUGA scan, and had not missed any doses in the 2 days preceding the MUGA scan was evaluated. Baseline value used for change from baseline calculation was defined as the pre-dose value. Reported values and changes from baseline were summarized in a descriptive fashion.

\section{QT/QTc interval analysis}

For patients to be valid for QT/QTc analysis, they had to receive sorafenib treatment and have at a minimum 1 set of triplicate baseline ECG data and 1 set of triplicate postsorafenib ECG data. The primary analysis of the effect of sorafenib on QT/QTc was the change in QT/QTc interval from baseline at the maximum concentration of sorafenib $\left(t_{\max }\right)$. Baseline was defined as the QT/QTc measurements recorded on the placebo dosing day at the same time as $t_{\max }$ based on sorafenib plasma concentrations post-baseline. Secondary analyses included the change in QT/QTc interval from baseline over a 12-h period where baseline was the corresponding measurement at the same time point on the placebo dosing day, and the maximal change from baseline over the 12-h period where baseline was the corresponding measurement at the same time point on the placebo dosing day when $t_{\max }$ was observed post-baseline. Reported values and changes from baseline were summarized in a descriptive fashion. Changes in QT/QTc interval caused by moxifloxacin were evaluated from baseline by time point where baseline was the corresponding measurement at the same time point on the placebo dosing day. For QTc evaluation, Fridericia's correction formula $\left(\mathrm{QTcF}=\mathrm{QT} / \mathrm{RR}^{1 / 3}\right)$ was used to correct for $\mathrm{HR}$, where $\mathrm{RR}=60 / \mathrm{HR}$. Bazett's correction formula $(\mathrm{QTcB}=\mathrm{QT} /$ $\mathrm{RR}^{1 / 2}$ ) was also used.

\section{Blood pressure and heart rate analysis}

For patients to be valid for BP and HR analyses, they had to receive sorafenib treatment and have at minimum 1 set each of duplicate baseline and duplicate post-sorafenib BP and HR data. The primary analysis of the effect of sorafenib on BP and HR was the change from baseline at the maximum concentration $\left(t_{\max }\right)$ of sorafenib. Secondary analyses included the change from baseline in BP/HR over a 12-h period and the maximal change from baseline over the 12 -h period. Reported values and changes from baseline were summarized in a descriptive fashion. Baseline values for analyses evaluating change from baseline at $t_{\max }$ of sorafenib by time point and maximal change were similar to those defined for other cardiovascular parameters. 
Pharmacokinetic analysis

The pharmacokinetic parameters were calculated using the model-independent (compartment-free) method (WinNonlin, Pharsight Corporation, Mountain View, CA, USA). Summary statistics of plasma concentrations and derived pharmacokinetic variables at each sampling time were analyzed by time point. Ratio of AUC and $C_{\max }$ at day 1 of cycle 5 to day 1 of cycle 2 were evaluated to determine the extent of accumulation, if any.

Safety and efficacy analyses

All patients who received at least 1 dose of sorafenib were included in the safety analysis. Incidence rates of treatment-emergent AEs, including relation to drug and seriousness, were evaluated descriptively according to the NCI-CTCAE v3.0. All patients who received $\geq 1$ dose of sorafenib were included in the efficacy assessment. Patients evaluable for objective overall tumor response required disease to be re-evaluated (baseline and post-baseline tumor evaluation) radiologically. Patients who discontinued because of death or disease progression before the tumor was re-evaluated were also evaluable. Descriptive statistics summarized objective overall tumor response rate (complete response $[\mathrm{CR}]$ and partial response $[\mathrm{PR}]$ ) and best response assessment using the RECIST criteria, and descriptive Kaplan-Meier statistics were used to evaluate efficacy parameters such as PFS.

\section{Results}

Patient characteristics

Fifty-three patients were enrolled and treated in the study. Patient baseline demographics are shown in Table 2. The most common findings in the cardiovascular medical histories were hypertension $(n=25 ; 47.2 \%)$, tachycardia $(n=5 ; 9.4 \%)$, MI $(n=3 ; 5.7 \%)$, and CAD $(n=2 ; 3.8 \%)$. Most of the patients with a history of hypertension (22 of 25 patients) were taking antihypertensive medications at study entry. The number of patients who met the criteria for inclusion in the LVEF analysis was 32; QT/QTc interval analysis, 36; BP and HR analysis, 39; PK analysis, 27; safety and efficacy analysis, 53; and those evaluable for response, 47. The database used for all analyses was based on protocoldefined analyses of the cardiovascular safety parameters.

\section{LVEF results}

Mean (SD) baseline LVEF(\%) was 64.9 (7.0) in the primary patient group $(n=32$; those who received $\geq 1$ dose
Table 2 Patient baseline demographics, disease, and cardiovascular characteristics

Sorafenib $400 \mathrm{mg}$ bid $(N=53)$

\begin{tabular}{|c|c|}
\hline \multicolumn{2}{|l|}{ Demographic baseline characteristics } \\
\hline \multicolumn{2}{|l|}{ Race, $n(\%)$} \\
\hline Caucasian & $48(91)$ \\
\hline Hispanic & $5(9)$ \\
\hline \multicolumn{2}{|l|}{ Sex, $n(\%)$} \\
\hline Female & $21(40)$ \\
\hline Male & $32(60)$ \\
\hline Mean age, $y(\mathrm{SD})$ & $56.8(10.7)$ \\
\hline$<65$ years, $n(\%)$ & $41(77)$ \\
\hline$\geq 65$ years, $n(\%)$ & $12(23)$ \\
\hline \multicolumn{2}{|l|}{ Performance status (ECOG), $n(\%)$} \\
\hline 0 & $17(32)$ \\
\hline 1 & $33(62)$ \\
\hline 2 & $3(6)$ \\
\hline \multicolumn{2}{|l|}{ Cardiovascular risk assessment } \\
\hline Body mass index, ${ }^{\mathrm{a}}$ mean (SD) & $26.6(5.5)$ \\
\hline Obesity, $n(\%)$ & $4(8)$ \\
\hline Diabetes mellitus, $n(\%)$ & $5(9)$ \\
\hline Type 2 diabetes, $n(\%)$ & $2(4)$ \\
\hline Hypercholesterolemia, $n(\%)$ & $9(17)$ \\
\hline Hyperlipidemia, $n(\%)$ & $4(8)$ \\
\hline \multicolumn{2}{|l|}{ Baseline disease characteristics } \\
\hline Stage IV/IVb at study entry, $n(\%)$ & $53(100)$ \\
\hline \multicolumn{2}{|l|}{ Tumor type, $n(\%)$} \\
\hline Renal cell carcinoma & $11(21)$ \\
\hline Squamous cell carcinoma & $5(9)$ \\
\hline Papillary carcinoma (thyroid) & $3(6)$ \\
\hline Duct cell adenocarcinoma & $2(4)$ \\
\hline Mesothelioma & $2(4)$ \\
\hline Bone sarcoma & $2(4)$ \\
\hline Non-small cell lung carcinoma & $2(4)$ \\
\hline Prostate & $1(2)$ \\
\hline Other, including unknown primary & $26(47)$ \\
\hline \multicolumn{2}{|l|}{ Cardiovascular medical history, $n(\%)$} \\
\hline Hypertension & $25(47)$ \\
\hline Tachycardia & $5(9)$ \\
\hline Myocardial infarction & $3(6)$ \\
\hline Coronary artery disease & $2(4)$ \\
\hline Mitral valve prolapse & $2(4)$ \\
\hline Arrhythmia & $1(2)$ \\
\hline Congestive heart failure & $1(2)$ \\
\hline \multirow[t]{2}{*}{ Left atrial dilatation } & $1(2)$ \\
\hline & $n=32$ \\
\hline \multicolumn{2}{|l|}{$\begin{array}{l}\text { Baseline cardiovascular characteristics } \\
\text { (at estimated } t_{\max } \text { where indicated) }\end{array}$} \\
\hline $\operatorname{LVEF}(\%)$ (primary analysis group), mean (SD) & $64.9(7.0)$ \\
\hline
\end{tabular}


Table 2 continued

\begin{tabular}{|c|c|}
\hline & $n=32$ \\
\hline Systolic BP at $t_{\max }, \mathrm{b}$ mm Hg, mean (SD) & $123.5(23.0$ \\
\hline Diastolic BP at $t_{\max },{ }^{\mathrm{b}} \mathrm{mm} \mathrm{Hg}$, mean (SD) & $68.4(13.3$ \\
\hline \multirow[t]{2}{*}{ HR at $t_{\max },{ }^{b}$ bpm, mean (SD) } & $81.0(16.5$ \\
\hline & $n=31$ \\
\hline \multicolumn{2}{|l|}{$Q T / Q T c$ at $t_{\max }{ }^{b}{ }^{b}$ ms, mean $(S D)$} \\
\hline QT & $378.5(39.3$ \\
\hline QTcB & $437.6(16.4$ \\
\hline QTcF & $416.5(20.3$ \\
\hline
\end{tabular}

$S D$ standard deviation, ECOG Eastern cooperative oncology group, $B P$ blood pressure, $H R$ heart rate, $b p m$ beats per minute, $L V E F$ left ventricular ejection fraction, $Q T c F$ Fridericia's-corrected QT interval, QTCB Bazett's-corrected QT interval

${ }^{a}$ Mean body mass index was based on 52 patients

b Measurements from placebo dosing day at corresponding time point of $t_{\max }$ post-baseline

of sorafenib) and 65.58 (6.9) in the secondary patient group ( $n=25$; those who received at least $75 \%$ of all required doses of sorafenib). A minimal mean decline of 1.0 in $\operatorname{LVEF}(\%)$ occurred in both the primary patient group $(n=31)$ and the secondary patient group $(n=25)$ after 2 cycles of treatment (Table 3). After 4 cycles of sorafenib, mean declines of 1.2 and 1.4 in $\operatorname{LVEF}(\%)$ occurred in the primary $(n=24)$ and secondary $(n=14)$ patient groups, respectively. In the primary group, a decrease from baseline of $\geq 10 \operatorname{LVEF}(\%)$ was seen in 4 patients (12.9\%) after 2 cycles, and in 1 patient (4.3\%) after 4 cycles of sorafenib (Fig. 1). In the secondary group, a decrease from baseline of $\geq 10 \mathrm{LVEF}(\%)$ was found in 3 patients $(12.0 \%)$ after 2 cycles, and in 1 patient $(7.1 \%)$ after 4 cycles of sorafenib. These 4 patients all had multiple concurrent illnesses that may have contributed to the LVEF decreases (Table 4). The largest individual decrease in ejection fraction $(-24.8$ LVEF[\%]) was recorded in a patient who did not demonstrate clinical signs of CHF. Overall 2 patients (6.5\%) experienced a post-baseline shift to $\leq 50 \operatorname{LVEF}(\%)$, the above-mentioned patient and another patient after receiving 4 cycles of sorafenib; both of these patients are included in Table 4.

\section{QT/QTc interval results}

In 31 patients included in the primary QT/QTc analysis after 1 cycle of sorafenib treatment, mean increases from baseline of 9.0 and $4.2 \mathrm{~ms}$ were observed for QTcF and $\mathrm{QTcB}$, respectively, at the $t_{\max }$ of sorafenib, indicating a modest prolongation of the QT/QTc interval. No patient was observed to have a QTcB or QTcF value $>500 \mathrm{~ms}$ at any time during the study, and no patient showed a $\geq 60$-ms change from baseline in QTcB or QTcF. The maximum prolongation in either QTcB or QTcF was a $+50 \mathrm{~ms}$ change from QTcF baseline at $t_{\max }$ in 1 patient with an adenocarcinoma of unknown primary origin. The baseline QTcF for this patient was $396.7 \mathrm{~ms}$, and after 1 cycle of sorafenib treatment the value was $446.3 \mathrm{~ms}$. For the secondary analyses, the mean increases from baseline by time point ranged from 0.2 to 2.9 and 4.2 to $5.8 \mathrm{~ms}$ for QTcB and QTcF, respectively, again indicating a modest QT prolongation following continuous sorafenib treatment. The mean maximal increases from baseline were 16.4 and $19.8 \mathrm{~ms}$ for QTcB and QTcF, respectively. All QT/QTc results are shown in Table 5 .

\section{Blood pressure and heart rate results}

For the primary analysis, mean (SD) increases from baseline in supine systolic and diastolic BP of $11.7( \pm 19.0)$ and 11.0 $( \pm 12.3) \mathrm{mm} \mathrm{Hg}$, respectively, were observed at the $t_{\max }$ of sorafenib after 1 cycle of treatment $(n=31)$. Similar results were seen after 4 cycles in the 16 patients evaluable for BP (Table 3). In most patients, the BP values at each time point measure did not exceed 150/90 mm Hg. Four patients exceeded 150/90 $\mathrm{mm} \mathrm{Hg}$, another 4 patients exceeded a systolic reading of $150 \mathrm{~mm} \mathrm{Hg}$, and another 2 patients had a diastolic reading surpassing $90 \mathrm{~mm} \mathrm{Hg}$ after 1 cycle of sorafenib. After receiving 4 cycles of sorafenib only 2 patients exceeded 150/90 mm Hg. After 1 cycle of sorafenib, the secondary analyses of mean increases from baseline in supine BP by time point showed that the largest mean increase (15.9 and $12.2 \mathrm{~mm} \mathrm{Hg}$ for systolic and diastolic BP, respectively) occurred at $12 \mathrm{~h}$ post-sorafenib administration. The mean (SD) maximal increases from baseline for supine systolic and diastolic BP were $27.7( \pm 18.5)$ and $19.8( \pm 9.0)$ $\mathrm{mm} \mathrm{Hg}$, respectively, after 1 cycle of sorafenib. Compensatory mean changes from baseline in supine HR of -6.6 and $-3.3 \mathrm{bpm}$ were reported after 1 and 4 cycles of sorafenib in 30 and 13 evaluable patients, respectively. In secondary analyses, mean changes from baseline in supine HR by time point showed that after 1 cycle of sorafenib the largest mean change $(-6.0 \mathrm{bpm})$ occurred $6 \mathrm{~h}$ post-sorafenib administration. Mean (SD) maximal decreases from baseline in supine HR of $2.9( \pm 8.2) \mathrm{bpm}$ and $8.3( \pm 6.8) \mathrm{bpm}$ were reported after 1 and 4 cycles of sorafenib, respectively. Three patients started receiving antihypertensive medications during treatment with sorafenib.

\section{Pharmacokinetic results}

The PK data from this study are consistent with previous findings at the steady state of sorafenib in patients with cancer receiving sorafenib $400 \mathrm{mg}$ bid (Table 6). After 1 
Table 3 Mean changes from baseline in left ventricular ejection fraction and blood pressure/heart rate after treatment with sorafenib

\begin{tabular}{|c|c|c|c|c|c|c|}
\hline \multirow[t]{3}{*}{$\operatorname{LVEF}(\%)$} & \multicolumn{6}{|c|}{ Sorafenib $400 \mathrm{mg}$ bid } \\
\hline & $n$ & \multicolumn{2}{|c|}{ Mean (SD) change from baseline } & $n$ & \multicolumn{2}{|c|}{ Mean (SD) change from baseline } \\
\hline & \multicolumn{3}{|c|}{ Day 1 of cycle 3} & \multicolumn{3}{|c|}{ Day 1 of cycle 5} \\
\hline \multicolumn{7}{|l|}{ Change from baseline } \\
\hline Primary analysis population & 31 & \multicolumn{2}{|c|}{$-0.8(8.6)$} & 24 & \multicolumn{2}{|c|}{$-1.2(7.8)$} \\
\hline Secondary analysis population & 25 & \multicolumn{2}{|c|}{$-1.0(8.5)$} & 14 & \multicolumn{2}{|c|}{$-1.4(9.4)$} \\
\hline $\mathrm{BP} / \mathrm{HR}$ & \multicolumn{3}{|c|}{ Day 1 of cycle 2} & \multicolumn{3}{|c|}{ Day 1 of cycle 5} \\
\hline$\geq 150 / 90 \mathrm{~mm} \mathrm{Hg}$ at $t_{\max }, n(\%)$ & & 31 & $10^{\mathrm{a}}(32)$ & & 16 & $2^{\mathrm{b}}(13)$ \\
\hline \multicolumn{7}{|c|}{ Primary $\mathrm{BP} / \mathrm{HR}$ analysis ( $\mathrm{mm} \mathrm{Hg} / \mathrm{bpm})$} \\
\hline \multicolumn{7}{|l|}{ Change from baseline at $t_{\max }^{\mathrm{c}}$} \\
\hline Supine systolic BP & & 31 & $11.7(19.0)$ & & 16 & $11.1(11.8)$ \\
\hline Supine diastolic BP & & 31 & $11.0(12.3)$ & & 16 & $11.9(13.6)$ \\
\hline Supine HR & & 30 & $-6.6(10.6)$ & & 13 & $-3.3(7.3)$ \\
\hline \multicolumn{7}{|c|}{ Secondary $\mathrm{BP} / \mathrm{HR}$ analyses $(\mathrm{mm} \mathrm{Hg} / \mathrm{bpm})$} \\
\hline \multicolumn{7}{|l|}{ Change from baseline over time ${ }^{\mathrm{d}}$} \\
\hline \multicolumn{7}{|l|}{ Supine systolic BP } \\
\hline Pre-dose $e^{e}$ & & 34 & $9.1(18.9)$ & & 19 & $13.4(13.9)$ \\
\hline $2 \mathrm{~h}$ & & 35 & $8.2(19.8)$ & & 19 & $13.3(18.6)$ \\
\hline $4 \mathrm{~h}$ & & 34 & $11.7(20.8)$ & & 18 & $11.0(18.1)$ \\
\hline $6 \mathrm{~h}$ & & 35 & $13.8(20.4)$ & & 19 & $15.4(15.7)$ \\
\hline $8 \mathrm{~h}$ & & 34 & $14.8(20.8)$ & & 19 & $12.4(15.4)$ \\
\hline $12 \mathrm{~h}$ & & 34 & $15.9(18.8)$ & & 18 & $12.9(16.0)$ \\
\hline \multicolumn{7}{|l|}{ Supine diastolic BP } \\
\hline Pre-dose $e^{e}$ & & 34 & $7.6(14.0)$ & & 19 & $11.1(12.8)$ \\
\hline $2 \mathrm{~h}$ & & 35 & $7.4(11.5)$ & & 19 & $11.4(13.1)$ \\
\hline $4 \mathrm{~h}$ & & 34 & 10.8 (11.6) & & 18 & $11.8(13.2)$ \\
\hline $6 \mathrm{~h}$ & & 35 & $11.3(13.0)$ & & 19 & $13.6(11.4)$ \\
\hline $8 \mathrm{~h}$ & & 34 & $11.0(12.4)$ & & 19 & $14.4(13.5)$ \\
\hline $12 \mathrm{~h}$ & & 34 & $12.2(9.7)$ & & 18 & $9.1(12.0)$ \\
\hline \multicolumn{7}{|l|}{ Supine HR } \\
\hline Pre-dose $e^{e}$ & & 33 & $-4.4(8.1)$ & & 16 & $-2.9(10.0)$ \\
\hline $2 \mathrm{~h}$ & & 35 & $-5.4(9.2)$ & & 16 & $-0.03(7.1)$ \\
\hline $4 \mathrm{~h}$ & & 34 & $-4.0(8.8)$ & & 16 & $0.1(9.2)$ \\
\hline $6 \mathrm{~h}$ & & 35 & $-6.0(8.9)$ & & 16 & $0(8.7)$ \\
\hline $8 \mathrm{~h}$ & & 34 & $-4.2(11.3)$ & & 16 & $0.7(8.6)$ \\
\hline $12 \mathrm{~h}$ & & 34 & $-5.8(13.3)$ & & 15 & $1.6(10.0)$ \\
\hline \multicolumn{7}{|l|}{ Maximal change from baseline ${ }^{f}$} \\
\hline Supine systolic BP & & 35 & $27.7(18.5)$ & & 19 & $24.8(14.4)$ \\
\hline Supine diastolic BP & & 35 & $19.8(9.0)$ & & 19 & $22.0(11.2)$ \\
\hline Supine HR & & 35 & $2.9(8.2)$ & & 16 & $8.3(6.8)$ \\
\hline
\end{tabular}

$L V E F$ left ventricular ejection fraction, $S D$ standard deviation, $B P$ blood pressure, $H R$ heart rate, $b p m$ beats per minute

${ }^{\mathrm{a}}$ Four patients had both systolic and diastolic $\geq 150 / 90 \mathrm{~mm} \mathrm{Hg}, 4$ patients had only systolic $\geq 150 \mathrm{~mm} \mathrm{Hg}, 2$ patients had only diastolic $\geq 90 \mathrm{~mm}$ $\mathrm{Hg}$

b Two patients exceeded only diastolic $\geq 90 \mathrm{~mm} \mathrm{Hg}$

c Measurements from placebo dosing day at corresponding time point of $t_{\max }$ post-baseline were used as the baseline values for analysis

d Measurements from placebo dosing day at each corresponding time point post-baseline were used as the baseline values for analysis

e Pre-dose: Measurements taken before the administration of placebo (baseline) or sorafenib (on day 1 of cycle 2)

${ }^{\mathrm{f}}$ Measurements from placebo dosing day at corresponding time point maximum value observed post-baseline were used as the baseline values for analysis 

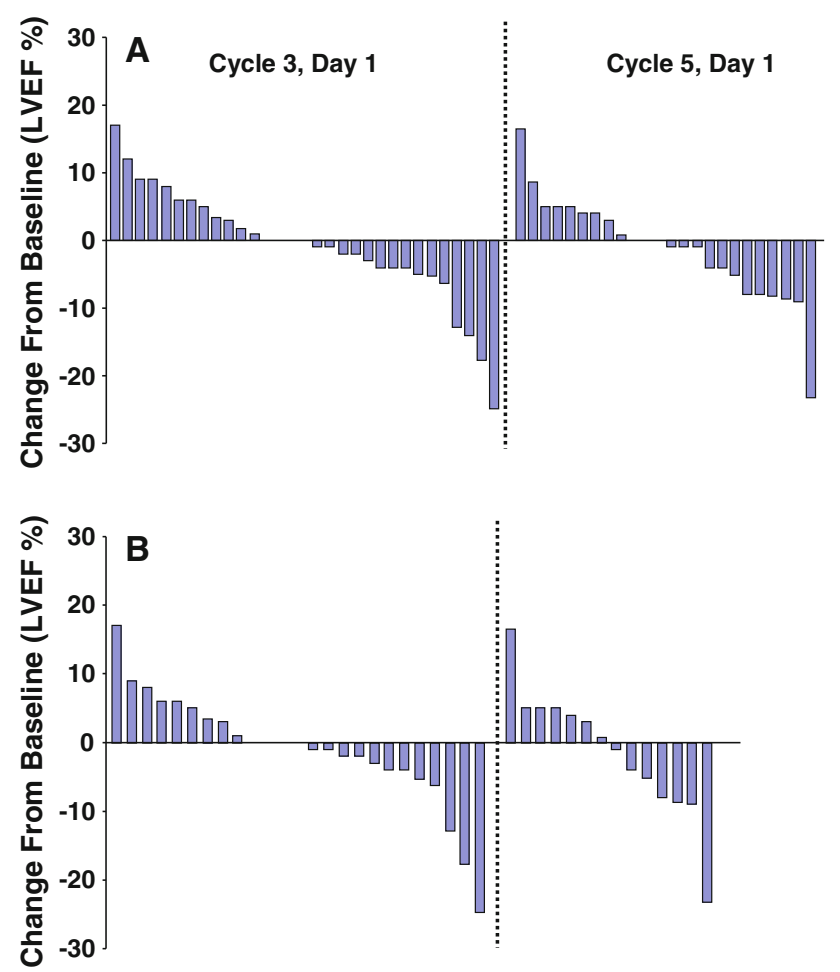

Fig. 1 Left ventricular ejection fraction (LVEF [\%]) changes from baseline after sorafenib treatment in all patients in the primary analysis group (31 patients and 24 patients on day 1 of cycles 3 and 5, respectively) (a) and the secondary analysis group (25 patients and 14 patients on day 1 of cycles 3 and 5, respectively) (b)

cycle of sorafenib, the $\mathrm{AUC}_{(0-12)}$ geometric mean $(\% \mathrm{CV})$ was $42.8 \mathrm{mg} \mathrm{h} / \mathrm{L}(36.1 \%)$ and the $C_{\max }$ geometric mean (\% $\mathrm{CV})$ was $5.4 \mathrm{mg} / \mathrm{L}(53.2 \%)$. A general trend toward a decrease in both $\mathrm{AUC}_{(0-12)}$ and $C_{\max }$ of sorafenib occurred in patients receiving more than 1 cycle of treatment. This trend was stronger for all of the metabolites than for sorafenib. The observed decrease may be due to an unreported lack of adherence, a common issue with oral medications. The relationship between PK parameters $\left(\mathrm{AUC}_{(0-12)}, C_{\max }\right)$ and cardiovascular safety parameters (QT/QTc, LVEF, BP, and HR) was explored by correlating PK parameters after 1 cycle of sorafenib to QT/QTc interval and BP and HR after 1 cycle and to LVEF after 2 cycles of sorafenib. An additional analysis was performed to evaluate the correlation of PK parameters with LVEF, $\mathrm{BP}$, and HR following 4 cycles of sorafenib. No relationship was observed between any of the PK parameters and the cardiovascular safety parameters at any time point (data not shown).

Safety and efficacy results

Median daily dose in the 53 patients valid for the safety analysis was $800 \mathrm{mg}$ of sorafenib (range 133-800 mg).
The median duration of treatment was 16 weeks (range 1-128 weeks) with 14 (26.4\%) patients receiving sorafenib for longer than 24 weeks and $6(11 \%)$ patients longer than 50 weeks. Treatment interruptions and dose reductions occurred in $40(75.5 \%)$ and $23(43.4 \%)$ patients, respectively, with treatment-emergent AEs being the reason for treatment interruptions in 23 (43.4\%) patients and for dose reductions in $17(32.1 \%)$ patients. Drug-related treatmentemergent AEs were reported in $43(81 \%)$ patients, and drug-related treatment-emergent $\mathrm{AEs} \geq$ grade 3 were reported in 16 (30\%) patients (Table 7). The most common drug-related treatment-emergent AEs were rash/desquamation, hand-foot skin reaction (HFSR), and diarrhea. Two (4\%) patients reported drug-related treatment-emergent serious AEs (SAEs). One patient with metastatic RCC, a history of breast cancer, hypertension (managed with an oral calcium-channel blocker), heart attack, and right internal carotid stenosis experienced a complete atrioventricular block (grade 3) that promptly resolved upon implantation of a permanent dual chamber pacemaker. One patient with advanced mesothelioma and an extensive cardiovascular medical history (CAD status post-left heart catheterization and CHF, MI, angioplasty, angina pectoris, and hypertension managed with a beta blocker) had grade 4 central nervous system (CNS) ischemia. One patient with thymic carcinoma and a baseline LVEF value of $72 \%$ reported CHF that was clearly secondary to a pulmonary embolism (PE) and considered by the investigator to be unrelated to sorafenib treatment. Other AEs that this patient reported during the $\mathrm{CHF}$ episode were grade 2 dyspnea on exertion, grade 2 atrial flutter (AFl), grade 2 pleural effusion, and grade 1 hypotension. LVEF by echocardiogram (ECHO) was measured as $25 \%$ during the hospital confinement. However, this value is confounded by the use of ECHO instead of MUGA scan and the presence of $\mathrm{PE}$ and $\mathrm{AFl}$. Upon aggressive treatment for the $\mathrm{AFl}$ and PE, the LVEF value returned to normal (60-65\%), and the patient resumed treatment with sorafenib without further significant AEs. Seven patients discontinued from the study because of AEs, 3 of which were drug-related, including 1 patient with grade 3 HFSR, 1 patient with grade 3 scalp rash, and the 1 patient with the grade 3 atrioventricular block. Seven deaths were reported during the study or within 30 days of the last dose; all were secondary to disease progression and considered unrelated to study drug.

Data used for efficacy analyses were based on protocoldefined analyses of the cardiovascular safety parameters. Of the $48(91 \%)$ patients evaluable for tumor response, 1 (2.1\%) female patient with mesothelioma achieved a PR, $31(65 \%)$ patients had stable disease, and $13(27 \%)$ patients had PD as best response. For the intent to treat (ITT) population $(n=53)$, median overall survival was not 


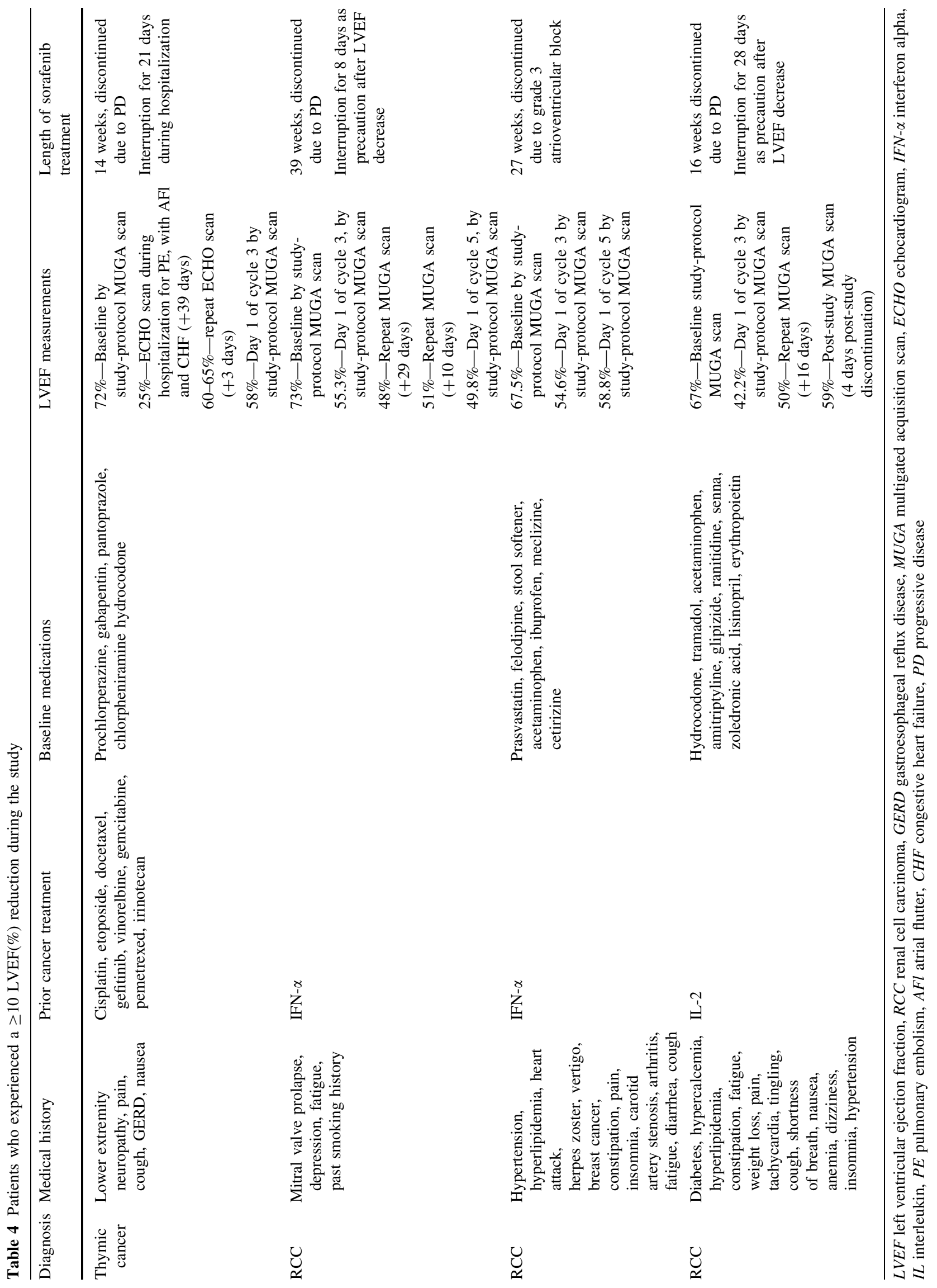


Table 5 Changes in QT/QTc interval after 1 cycle of sorafenib treatment (on day 1 of cycle 2)

\begin{tabular}{|c|c|c|c|c|}
\hline & \multicolumn{4}{|c|}{ Sorafenib $400 \mathrm{mg}$ bid } \\
\hline & \multicolumn{4}{|c|}{ Mean (SD) change from baseline } \\
\hline & $n$ & QT (ms) & $\mathrm{QTcB}(\mathrm{ms})$ & QTcF (ms) \\
\hline & \multicolumn{4}{|c|}{ Day 1 of cycle 2} \\
\hline \multicolumn{5}{|l|}{ Primary ECG analysis } \\
\hline Change from baseline at $t_{\max }^{\mathrm{a}}$ & 31 & $17.4(29.3)$ & $4.2(19.2)$ & $9.0(18.0)$ \\
\hline \multicolumn{5}{|l|}{ Secondary ECG analyses } \\
\hline \multicolumn{5}{|l|}{ Change from baseline over time ${ }^{b}$} \\
\hline Pre-dose $e^{c}$ & 34 & $12.3(26.6)$ & $1.1(18.3)$ & $5.2(18.3)$ \\
\hline $2 \mathrm{~h}$ & 35 & $10.6(27.8)$ & $0.5(18.0)$ & $4.2(17.9)$ \\
\hline $4 \mathrm{~h}$ & 35 & $10.7(29.4)$ & $2.0(20.2)$ & $5.2(19.4)$ \\
\hline $6 \mathrm{~h}$ & 35 & $13.1(27.0)$ & $1.6(17.3)$ & $5.7(18.1)$ \\
\hline $8 \mathrm{~h}$ & 35 & $12.2(27.3)$ & $0.2(16.1)$ & $4.5(14.4)$ \\
\hline $12 \mathrm{~h}$ & 31 & $10.6(29.6)$ & $2.9(17.2)$ & $5.8(19.1)$ \\
\hline Maximal change from baseline ${ }^{\mathrm{d}}$ & 36 & $32.9(24.1)$ & $16.4(15.3)$ & $19.8(14.4)$ \\
\hline \multicolumn{5}{|l|}{ Moxifloxacin (positive control) } \\
\hline Change from baseline at $2 \mathrm{~h}$ post-dose $\mathrm{b}^{\mathrm{b}}$ & 49 & $5.7(24.3)$ & $4.4(12.9)$ & 4.9 (13.7) \\
\hline
\end{tabular}

$E C G$ electrocardiograph, $S D$ standard deviation, $Q T c F$ Fridericia's-corrected QT interval, $Q T c B$ Bazett's-corrected QT interval

${ }^{a}$ Measurements from placebo dosing day at corresponding time point of $t_{\max }$ post-baseline were used as the baseline values for analysis

b Measurements from placebo dosing day at each corresponding time point post-baseline were used as the baseline values for analysis

${ }^{c}$ Pre-dose: Measurements taken before the administration of placebo (baseline) or sorafenib (on day 1 of cycle 2)

${ }^{\mathrm{d}}$ Measurements from placebo dosing day at corresponding time point maximum value observed post-baseline were used as the baseline values for analysis

estimable due to censored data; $46(87 \%)$ patients were alive (censored) and 7 (13\%) patients had died by the time of analysis. The median PFS was 4.1 months (95\% CI 2.86.4 months).

\section{Discussion}

This cardiovascular safety trial of sorafenib in 53 patients with advanced cancer assessed the effect of sorafenib on various cardiovascular parameters. There was little evidence of an overall decrement in ejection fraction from baseline in patients with cancer treated with sorafenib $400 \mathrm{mg}$ bid; however, both increases and decreases were observed in LVEF, and isolated patients had a $\geq 10$ $\operatorname{LVEF}(\%)$ decrease in ejection fraction, as measured by serial MUGA scans. These modest changes in LVEF would not be entirely unexpected in a population of patients with metastatic cancer whose overall health is generally deteriorating over time.

This study should be put in context with other studies of multitargeted kinase inhibitors of VEGFR. Several studies have reported an association between sunitinib, another multitargeted TKI, and heart failure and/or a $\geq 10$ $\operatorname{LVEF}(\%)$ reduction [1, 4-10]. An observational study by Schmidinger et al. analyzed patients who had received treatment with antiangiogenic therapy (either sunitinib or sorafenib) in their clinic. The incidence of $\geq 10 \mathrm{LVEF}(\%)$ reduction was $14 \%$ in patients receiving sunitinib and $5 \%$ in patients receiving sorafenib [4, 24]. Similar results were seen in our detailed cardiovascular study, with $a \geq 10$ $\operatorname{LVEF}(\%)$ reduction reported in $13 \%$ of patients after 2 cycles of sorafenib and in $4 \%$ of patients after 4 cycles of sorafenib. In the study by $\mathrm{Chu}$ et al. the mean change after 2 and 4 cycles of sunitinib was $-2.2 \operatorname{LVEF}(\%)$ and -5.1 $\operatorname{LVEF}(\%)$, respectively [5], compared with the results in this study of -0.8 and -1.2 seen after 2 and 4 cycles of sorafenib. In light of this, it is also encouraging to find that in this phase I study of sorafenib, the number of patients receiving sorafenib treatment who had a $\geq 10 \% \operatorname{LVEF}(\%)$ reduction was low, but a direct comparison without a randomized study is not possible. A recent study by Hutson et al. reported declines to $<50 \mathrm{LVEF}(\%)$ in $12 \%$ of patients after 1 cycle ( 6 weeks), $10 \%$ of patients after 1 year, and $5 \%$ of patients after 2 years of sunitinib, suggesting a minimal cumulative effect on LVEF with long-term treatment with an antiangiogenic TKI [10].

Delays in cardiac repolarization after treatment can lead to arrhythmias such as torsades de pointes (TdP) or other ventricular tachyarrhythmias that can result in ventricular fibrillation and, occasionally, sudden death [25]. There is increasing regulatory scrutiny of the effects of novel 
Table 6 Pharmacokinetic parameters in plasma at steady state of sorafenib

\begin{tabular}{|c|c|c|c|}
\hline \multirow[t]{2}{*}{ Geometric mean $(\% \mathrm{CV})$} & \multicolumn{3}{|c|}{ Sorafenib $400 \mathrm{mg}$ bid } \\
\hline & $\begin{array}{l}\text { Day } 1 \text { of cycle } 2 \\
(n=17)^{\mathrm{a}}\end{array}$ & $\begin{array}{l}\text { Day } 1 \text { of cycle } 5 \\
(n=17)^{\mathrm{a}}\end{array}$ & $\begin{array}{l}\text { Ratio }^{\mathrm{b}}(90 \% \mathrm{CI}) \\
(n=17)^{\mathrm{a}}\end{array}$ \\
\hline \multicolumn{4}{|l|}{ Sorafenib } \\
\hline $\mathrm{AUC}, \mathrm{mg} \mathrm{h} / \mathrm{L}$ & $42.8(36.1)$ & $36.0(58.2)$ & $0.84(0.69-1.02)$ \\
\hline $\mathrm{AUC}_{\text {norm }}, \mathrm{kg} \mathrm{h} / \mathrm{L}$ & $7.5(48.4)$ & $6.3(69.8)$ & \\
\hline$C_{\max }, \mathrm{mg} / \mathrm{L}$ & $5.4(53.2)$ & $4.3(62.1)$ & $0.79(0.66-0.94)$ \\
\hline$C_{\text {max,norm }}, \mathrm{kg} / \mathrm{L}$ & $1.0(64.9)$ & $0.8(72.5)$ & \\
\hline$C_{\text {trough }}, \mathrm{mg} / \mathrm{L}$ & $4.1(73.6)$ & $3.2(73.8)$ & $0.78(0.61-0.99)$ \\
\hline$C_{\text {trough,norm }}, \mathrm{kg} / \mathrm{L}$ & $0.7(85.4)$ & $0.6(83.8)$ & \\
\hline$t_{\max }, \mathrm{h}$, median (range) & $2.00(0-12.00)$ & $2.00(0-8.05)$ & \\
\hline \multicolumn{4}{|c|}{$N$-demethyl metabolite (BAY 43-9007) } \\
\hline AUC, mg h/L & $2.0(59.1)$ & $1.1(74.0)$ & $0.57(0.41-0.81)$ \\
\hline $\mathrm{AUC}_{\text {norm }}, \mathrm{kg} \mathrm{h} / \mathrm{L}$ & $0.4(62.8)$ & $0.2(80.9)$ & \\
\hline$C_{\max }, \mathrm{mg} / \mathrm{L}$ & $0.2(73.4)$ & $0.1(75.5)$ & $0.51(0.38-0.68)$ \\
\hline$C_{\text {max,norm }}, \mathrm{kg} / \mathrm{L}$ & $0.1(75.2)$ & $<0.1(78.2)$ & \\
\hline$C_{\text {trough }}, \mathrm{mg} / \mathrm{L}$ & $0.2(82.3)$ & $0.1(82.4)$ & $0.52(0.38-0.70)$ \\
\hline$C_{\text {trough, norm }}, \mathrm{kg} / \mathrm{L}$ & $<0.1(85.0)$ & $<0.1(84.8)$ & \\
\hline$t_{\max }, \mathrm{h}$, median (range) & $1.00(0-12.00)$ & $2.00(0-12.00)$ & \\
\hline \multicolumn{4}{|c|}{ N-oxide metabolite (BAY 67-3472) } \\
\hline AUC, mg h/L & $8.5(58.3)$ & $5.2(98.7)$ & $0.61(0.41-0.92)$ \\
\hline $\mathrm{AUC}_{\mathrm{norm}}, \mathrm{kg} \mathrm{h} / \mathrm{L}$ & $1.4(59.6)$ & $0.9(103.2)$ & \\
\hline$C_{\max }, \mathrm{mg} / \mathrm{L}$ & $1.0(66.8)$ & $0.6(96.9)$ & $0.58(0.41-0.82)$ \\
\hline$C_{\text {max,norm }}, \mathrm{kg} / \mathrm{L}$ & $0.2(70.2)$ & $0.1(100.7)$ & \\
\hline$C_{\text {trough }}, \mathrm{mg} / \mathrm{L}$ & $0.8(81.1)$ & $0.5(109.4)$ & $0.54(0.36-0.81)$ \\
\hline$C_{\text {trough }}$, norm, $\mathrm{kg} / \mathrm{L}$ & $0.1(85.9)$ & $0.1(111.5)$ & \\
\hline$t_{\max }, \mathrm{h}$, median (range) & $1.00(0-12.00)$ & $2.00(0-8.12)$ & \\
\hline \multicolumn{4}{|c|}{ N-oxide metabolite of BAY 43-9007 metabolite (BAY 68-7769) } \\
\hline $\mathrm{AUC}, \mathrm{mg} \mathrm{h} / \mathrm{L}$ & $2.8(92.3)$ & $1.4(129.3)$ & $0.50(0.28-0.89)$ \\
\hline $\mathrm{AUC}_{\text {norm }}, \mathrm{kg} \mathrm{h} / \mathrm{L}$ & $0.5(91.4)$ & $0.3(128.1)$ & \\
\hline$C_{\max }, \mathrm{mg} / \mathrm{L}$ & $0.3(101.6)$ & $0.2(127.2)$ & $0.47(0.28-0.80)$ \\
\hline$C_{\text {max,norm }}, \mathrm{kg} / \mathrm{L}$ & $0.1(99.6)$ & $<0.1$ (123.6) & \\
\hline$C_{\text {trough }}, \mathrm{mg} / \mathrm{L}$ & $0.3(114.5)$ & $0.1(127.8)$ & $0.49(0.29-0.83)$ \\
\hline$C_{\text {trough }}$, norm, $\mathrm{kg} / \mathrm{L}$ & $0.1(113.5)$ & $<0.1(124.7)$ & \\
\hline$t_{\max }, \mathrm{h}$, median (range) & $2.00(0-12.00)$ & $2.00(0-8.05)$ & \\
\hline
\end{tabular}

$A U C$ area under the curve, $C I$ confidence interval, $C V$ coefficient of variation, $C_{\max }$ maximum concentration, $C_{\text {trough }}$ trough concentration, $t_{\max }$ time to maximum concentration

${ }^{\mathrm{a}} n=14$ for area under the curve (AUC) analysis

b Ratio of day 1 of cycle 5 versus day 1 of cycle 2

oncology drugs on cardiac repolarization to assess the potential for life-threatening arrhythmias [26]. This is the first full in-depth analysis of the effect of sorafenib treatment on QT/QTc interval prolongation. Moxifloxacin, a quinolone antibiotic, was selected as the positive control in this study because it has a well-documented ability to prolong cardiac repolarization [22]. The QT/QTc interval prolongation observed with moxifloxacin in this study was within the range of those reported in other studies [27, 28], indicating that the methodology used was sensitive enough to detect small changes in the QT/QTc interval. Because increases in the risk of arrhythmias correlate with the extent of QT/QTc interval prolongation, drugs that prolong the mean QT/QTc interval by $\leq 5 \mathrm{~ms}$ are generally considered to cause no relevant QTc prolongation. In this study, the mean maximal increases from baseline (QTcB: $16 \mathrm{~ms}$; QTcF: $20 \mathrm{~ms}$ ) indicate that sporadic QT/QTc interval prolongation up to these values can occur 
Table 7 Drug-related treatment-emergent adverse events occurring in $\geq 10 \%$ of patients (all grades)

\begin{tabular}{lll}
\hline & \multicolumn{2}{l}{ Number of patients $(N=53)$} \\
\cline { 2 - 3 } & All grades $n(\%)$ & Grade $\geq 3 n(\%)$ \\
\hline Any drug-related adverse event & $43(81)$ & $16(30)$ \\
Rash/desquamation & $20(38)$ & $3(6)$ \\
Hand-foot skin reaction & $16(30)$ & $6(11)$ \\
Diarrhea & $15(28)$ & $1(2)$ \\
Alopecia & $13(25)$ & $0(0)$ \\
Pain, extremity—limb & $12(23)$ & $0(0)$ \\
Mucositis & $8(15)$ & $1(2)$ \\
Fatigue & $8(15)$ & $1(2)$ \\
Nausea & $7(13)$ & $0(0)$ \\
Dermatology-other & $7(13)$ & $1(2)$ \\
Sensory neuropathy & $7(13)$ & $0(0)$ \\
Hypertension & $6(11)$ & $1(2)$ \\
Dermal change & $6(11)$ & $0(0)$ \\
\hline
\end{tabular}

following continuous treatment with sorafenib. However, in the absence of a placebo group and a crossover design, it was not possible to define the maximal effect on QT/QTc interval prolongation occurring in the sorafenib-treated population with advanced cancer in this study. For this reason, increases from baseline of 9 and $4 \mathrm{~ms}$ observed for $\mathrm{QTcF}$ and QTcB, respectively, at the $t_{\max }$ of sorafenib are the best estimate of the effect of sorafenib on QTc prolongation, and based on the results of this detailed QT study, demonstrate the absence of a likely clinically relevant effect of sorafenib at therapeutic $(400 \mathrm{mg}$ bid) doses on cardiac repolarization. In a recent evaluation of the effects of sunitinib on the QT/QTc interval of 24 patients with advanced cancer with a similar baseline QTcF (411.8 ms), the maximum placebo-adjusted, time-matched QTcF and QTcB prolongations at $24 \mathrm{~h}$ post-sunitinib (50 mg daily) on the third day of treatment were 9.6 (90\% CI 4.1-15.1) and $7.9 \mathrm{~ms}$ (90\% CI 3.0-12.8), respectively [28]. In the study there was an increase in QTcF prolongation with increasing total drug concentrations.

The direct effect of sorafenib on mean change from baseline in BP at the $t_{\max }$ of sorafenib was similar after both 1 and 4 cycles of sorafenib treatment. Both the systolic and diastolic BP increased $\sim 11-12 \mathrm{~mm} \mathrm{Hg}$ at both time points, indicating a definite but modest increase in BP with sorafenib. Thirty-two percent of patients had become hypertensive after 1 cycle of treatment with sorafenib, up from $6 \%$ at baseline. However, the rate dropped to $13 \%$ of patients at cycle 4 . This may be due to the physiologic increase in vascular tension resulting from VEGF inhibition, or more likely, the increased use of antihypertensive medication to control the treatment-emergent hypertension. There were minimal decreases in HR following 1 cycle of sorafenib, which normalized after 4 cycles. The moderate changes observed in BP and HR are consistent with expectations for agents that inhibit signaling through the VEGF pathway.

By inhibiting angiogenesis, therapies that target VEGF (i.e., sorafenib, sunitinib, bevacizumab) increase hypertension in patients [29-32] and may increase the incidence of CAEs due to pleiotropic effects on the vasculature and cardiac tissues. The prevalence of hypertension with the use of antiangiogenic agents is so common that elevation in BP during treatment has been proposed as a candidate biomarker for VEGF inhibition [33-38]. Of note, the patient with the best tumor response to sorafenib in this study (confirmed PR) had the highest mean increase from baseline in both systolic and diastolic BP after both 1 and 4 cycles of sorafenib (systolic BP: 44.5 and $29.3 \mathrm{~mm} \mathrm{Hg}$, respectively, and diastolic BP: 31.0 and $40.8 \mathrm{~mm} \mathrm{Hg}$, respectively). However, although the incidence of hypertension after treatment with agents that inhibit VEGF has been well established, it should still be adequately treated and carefully monitored [24, 39]. Early recognition and proactive management of hypertension are important to avoid poorly controlled hypertension that can lead to serious CAEs.

$\mathrm{AUC}_{(0-12)}$ and $C_{\max }$ were similar in this study for sorafenib and its metabolites (BAY 43-9007, BAY 67-3472, BAY 68-7769) to results from previous studies in patients with cancer [23, 40, 41]. There was no apparent relationship between mean plasma exposure and cardiotoxicity. A small decrease in $\mathrm{AUC}_{(0-12)}$ and $C_{\max }$ from 1 cycle to 4 cycles of treatment was seen for sorafenib and its 3 metabolites. Although the reason for this decrease in exposure is not known, the time course of the effect suggests that an induction of metabolism is an unlikely cause. Lack of compliance may be a contributing reason for the decreasing trend in mean plasma concentration of sorafenib and its metabolites after 3 cycles of treatment.

Although this study reported modest cardiovascular effects of continuous sorafenib in patients with advanced cancer, the difficulty of carrying out this study in healthy volunteers precludes a broader definition of the cardiovascular profile of sorafenib. In addition, obtaining precise cardiovascular evaluations of sorafenib in the setting of a population with advanced cancer is limited by ethical and other medical considerations, including the absence of a placebo group, the difficulty in evaluating patients for the duration of a study with a crossover design, as is often done in healthy volunteer QT studies, multiple comorbidities and changes in the physiological status of cancer patients over time, and the inability to restrict the use of concomitant medications by the patients.

The successful management of treatment-emergent cardiac comorbidities and asymptomatic signs of 
cardiotoxicity is required to maximize the clinical benefit for patients with cancer being treated with antiangiogenic agents [8, 24, 42, 43]. The reversibility of CAEs and the effect of a CAE on a patient must be considered during treatment with such therapies. When assessing whether a patient should continue antiangiogenic treatment after a CAE has resolved, the life-prolonging benefit and improvement in quality of life that antiangiogenic treatment may offer to patients with advanced cancer must be considered. In many instances, patients may be able to continue treatment at a lower dose or switch to another antiangiogenic therapy without incurring new cardiovascular damage [4, 44]. However, additional studies are needed to define the circumstances under which antiangiogenic treatment may be undertaken without risking cardiac damage in patients $[45,46]$.

\section{Conclusion}

This study was specifically designed to assess the cardiovascular effects of continuous sorafenib treatment in a patient population with advanced cancer; however, the results from these cardiovascular analyses should be interpreted with caution due to the descriptive nature of the study design and limited sample size. Overall, the effects of continuous sorafenib on the cardiovascular parameters of QTc interval and LVEF observed in the current study were modest and unlikely to be of clinical significance in the setting of advanced cancer treatment. The effects of continuous sorafenib on BP and HR were moderate and consistent with expectations based on experience with other anti-VEGF targeting agents.

Acknowledgments This study was supported by Bayer HealthCare Pharmaceuticals-Onyx Pharmaceuticals. We thank the study participants and their families; study center staff; the clinical data management team at Bayer HealthCare Pharmaceuticals Inc; and Aurora O'Brate, $\mathrm{PhD}$, from Ogilvy Healthworld, who was supported by Bayer HealthCare Pharmaceuticals Inc, to provide editorial support for the preparation of this manuscript.

Open Access This article is distributed under the terms of the Creative Commons Attribution Noncommercial License which permits any noncommercial use, distribution, and reproduction in any medium, provided the original author(s) and source are credited.

\section{References}

1. Khakoo AY, Kassiotis CM, Tannir N et al (2008) Heart failure associated with sunitinib malate: a multitargeted receptor tyrosine kinase inhibitor. Cancer 112:2500-2508

2. Kerkela R, Grazette L, Yacobi R et al (2006) Cardiotoxicity of the cancer therapeutic agent imatinib mesylate. Nat Med 12:908916
3. Machiels JP, Bletard N, Pirenne P et al (2008) Acute cardiac failure after sunitinib. Ann Oncol 19:597-599

4. Schmidinger M, Zielinski CC, Vogl UM et al (2008) Cardiac toxicity of sunitinib and sorafenib in patients with metastatic renal cell carcinoma. J Clin Oncol 26:5204-5212

5. Chu TF, Rupnick MA, Kerkela R et al (2007) Cardiotoxicity associated with tyrosine kinase inhibitor sunitinib. Lancet 370:2011-2019

6. Wu CF, Chuang WP, Li AH, Hsiao CH (2009) Cardiac magnetic resonance imaging in sunitinib malate-related cardiomyopathy: no late gadolinium enhancement. J Chin Med Assoc 72:323-327

7. Telli ML, Witteles RM, Fisher GA, Srinivas S (2008) Cardiotoxicity associated with the cancer therapeutic agent sunitinib malate. Ann Oncol 19:1613-1618

8. Schmidinger M, Bojic A, Vogl UM, Lamm W, Zielinski CC (2009) Management of cardiac adverse events occurring with sunitinib treatment. Anticancer Res 29:1627-1629

9. Di Lorenzo G, Autorino R, Bruni G et al (2009) Cardiovascular toxicity following sunitinib therapy in metastatic renal cell carcinoma: a multicenter analysis. Ann Oncol 20:1535-1542

10. Hutson TE, Figlin RA, Tabesh M, Niculescu L, Motzer RJ (2010) Sunitinib-associated changes in left ventricular ejection fraction (LVEF) in treatment-naïve patients (pts) with metastatic renal cell carcinoma (mRCC). Am Soc Clin Oncol (Genitourinary cancers symposium Abstract 370)

11. Wilhelm SM, Carter C, Tang L et al (2004) BAY 43-9006 exhibits broad spectrum oral antitumor activity and targets the RAF/MEK/ERK pathway and receptor tyrosine kinases involved in tumor progression and angiogenesis. Cancer Res 64:7099-7109

12. Izumiya Y, Shiojima I, Sato K et al (2006) Vascular endothelial growth factor blockade promotes the transition from compensatory cardiac hypertrophy to failure in response to pressure overload. Hypertension 47:887-893

13. Chen MH, Kerkela R, Force T (2008) Mechanisms of cardiac dysfunction associated with tyrosine kinase inhibitor cancer therapeutics. Circulation 118:84-95

14. Hasinoff BB, Patel D, O'Hara KA (2008) Mechanisms of myocyte cytotoxicity induced by the multiple receptor tyrosine kinase inhibitor sunitinib. Mol Pharmacol 74:1722-1728

15. Will Y, Dykens JA, Nadanaciva S et al (2008) Effect of the multitargeted tyrosine kinase inhibitors imatinib, dasatinib, sunitinib, and sorafenib on mitochondrial function in isolated rat heart mitochondria and H9c2 cells. Toxicol Sci 106:153-161

16. Force T, Krause DS, Van Etten RA (2007) Molecular mechanisms of cardiotoxicity of tyrosine kinase inhibition. Nat Rev Cancer 7:332-344

17. Escudier B, Eisen T, Stadler WM et al (2007) Sorafenib in advanced clear-cell renal-cell carcinoma. N Engl J Med 356:125134

18. Llovet JM, Ricci S, Mazzaferro V et al (2008) Sorafenib in advanced hepatocellular carcinoma. N Engl J Med 359:378-390

19. Escudier B, Eisen T, Stadler WM et al (2009) Sorafenib for treatment of renal cell carcinoma: final efficacy and safety results of the phase III treatment approaches in renal cancer global evaluation trial. J Clin Oncol 27:3312-3318

20. Snow H, Brueckner A, Gelder M, Voliotis D, Kelley S (2008) Sorafenib is not associated with a high incidence of cardiovascular events in many tumor types. Ann Oncol 19:179

21. Sarapa N, Morganroth J, Couderc J-P et al (2004) Electrocardiographic identification of drug-induced QT prolongation: assessment by different recording and measurement methods. Ann Noninvasive Electrocardiol 1:48-57

22. Demolis JL, Kubitza D, Tenneze L, Funck-Brentano C (2000) Effect of a single oral dose of moxifloxacin (400 mg and $800 \mathrm{mg}$ ) on ventricular repolarization in healthy subjects. Clin Pharmacol Ther 68:658-666 
23. Clark JW, Eder JP, Ryan D, Lathia C, Lenz H-J (2005) Safety and pharmacokinetics of the dual action Raf kinase and vascular endothelial growth factor receptor inhibitor, BAY 43-9006 in patients with advanced, refractory solid tumors. Clin Cancer Res 11:5472-5480

24. Lenihan DJ (2008) Tyrosine kinase inhibitors: can promising new therapy associated with cardiac toxicity strengthen the concept of teamwork? J Clin Oncol 26:5154-5155

25. Recanatini M, Poluzzi E, Masetti M, Cavalli A, De PF (2005) QT prolongation through $\mathrm{hERG} \mathrm{K}(+)$ channel blockade: current knowledge and strategies for the early prediction during drug development. Med Res Rev 25:133-166

26. ICH Harmonised Tripartite Guideline (2005) The clinical evaluation of QT/QTc interval prolongation and proarrhythmic potential for non-antiarrhythmic. Drugs E14

27. Kubitza D, Mueck W, Becka M (2008) Randomized, doubleblind, crossover study to investigate the effect of rivaroxaban on QT-interval prolongation. Drug Saf 31:67-77

28. Bello CL, Mulay M, Huang X et al (2009) Electrocardiographic characterization of the QTc interval in patients with advanced solid tumors: pharmacokinetic-pharmacodynamic evaluation of sunitinib. Clin Cancer Res 15:7045-7052

29. Wu S, Chen JJ, Kudelka A, Lu J, Zhu X (2008) Incidence and risk of hypertension with sorafenib in patients with cancer: a systematic review and meta-analysis. Lancet Oncol 9:117-123

30. Zhu X, Stergiopoulos K, Wu S (2009) Risk of hypertension and renal dysfunction with an angiogenesis inhibitor sunitinib: systematic review and meta-analysis. Acta Oncol 48:9-17

31. Zhu X, Wu S, Dahut WL, Parikh CR (2007) Risks of proteinuria and hypertension with bevacizumab, an antibody against vascular endothelial growth factor: systematic review and meta-analysis. Am J Kidney Dis 49:186-193

32. Ranpura V, Pulipati B, Chu D, Zhu X, Wu S (2010) Increased risk of high-grade hypertension with bevacizumab in cancer patients: a meta-analysis. Am J Hypertens 23:460-468

33. Rini BI, Schiller JH, Fruehauf J et al (2008) Association of diastolic blood pressure $(\mathrm{dBP})>90 \mathrm{mmHg}$ with overall survival (OS) in patients treated with axitinib (AG- 013736). J Clin Oncol 26:3543

34. Dahlberg SE, Sandler AB, Brahmer JR, Schiller JH, Johnson DH (2010) Clinical course of advanced non-small-cell lung cancer patients experiencing hypertension during treatment with bevacizumab in combination with carboplatin and paclitaxel on ECOG 4599. J Clin Oncol 28:949-954
35. Rini BI, Cohen DP, Lu D et al. (2010) Hypertension (HTN) as a biomarker of efficacy in patients (pts) with metastatic renal cell carcinoma (mRCC) treated with sunitinib. Am Soc Clin Oncol (Genitourinary cancers symposium Abstract 312)

36. Rixe O, Dutcher J, Motzer R et al (2009) Diastolic blood pressure $(\mathrm{dBP})$ and pharmacokinetics (PK) as predictors of axitinib efficacy in metastatic renal cell cancer (mRCC). J Clin Oncol 27:5045

37. Scartozzi M, Galizia E, Chiorrini S et al (2009) Arterial hypertension correlates with clinical outcome in colorectal cancer patients treated with first-line bevacizumab. Ann Oncol 20:227-230

38. Maitland ML, Moshier K, Imperial J et al (2006) Blood pressure (BP) as a biomarker for sorafenib (S), an inhibitor of the vascular endothelial growth factor (VEGF) signaling pathway. J Clin Oncol 24:2035

39. Izzedine H, Ederhy S, Goldwasser F et al (2009) Management of hypertension in angiogenesis inhibitor-treated patients. Ann Oncol 20:807-815

40. Strumberg D, Richly H, Hilger RA et al (2005) Phase I clinical and pharmacokinetic study of the novel Raf kinase and vascular endothelial growth factor receptor inhibitor BAY 43-9006 in patients with advanced refractory solid tumors. J Clin Oncol 23:965-972

41. Strumberg D, Clark JW, Awada A et al (2007) Safety, pharmacokinetics, and preliminary antitumor activity of sorafenib: a review of four phase I trials in patients with advanced refractory solid tumors. Oncologist 12:426-437

42. van Heeckeren WJ, Bhakta S, Ortiz J et al (2006) Promise of new vascular-disrupting agents balanced with cardiac toxicity: is it time for oncologists to get to know their cardiologists? J Clin Oncol 24:1485-1488

43. Altena R, Perik PJ, van Veldhuisen DJ, de Vries EG, Gietema JA (2009) Cardiovascular toxicity caused by cancer treatment: strategies for early detection. Lancet Oncol 10:391-399

44. Wong MK, Jarkowski A (2009) Response to sorafenib after sunitinib-induced acute heart failure in a patient with metastatic renal cell carcinoma: case report and review of the literature. Pharmacotherapy 29:473-478

45. Mego M, Reckova M, Obertova J et al (2007) Increased cardiotoxicity of sorafenib in sunitinib-pretreated patients with metastatic renal cell carcinoma. Ann Oncol 18:1906-1907

46. Kamada P, Dudek AZ (2010) Sorafenib therapy for metastatic renal carcinoma in patients with low cardiac ejection fraction: report of two cases and literature review. Cancer Invest 28:501-504 